\title{
Erratum to: Changes in dural sac caliber with standing MRI improve correlation with symptoms of lumbar spinal stenosis
}

\author{
Yvonne Yan On Lau ${ }^{1,3} \cdot$ Ryan Ka Lok Lee ${ }^{2}$ James Francis Griffith ${ }^{2} \cdot$ \\ Carol Lai Yee Chan ${ }^{1}$ - Sheung Wai Law ${ }^{1} \cdot$ Kin On Kwok ${ }^{1}$
}

Published online: 3 August 2017

(C) Springer-Verlag GmbH Germany 2017

\section{Erratum to: Eur Spine J}

\section{DOI 10.1007/s00586-017-5211-7}

Unfortunately, the Fig. 3 published in the original article was incorrect. The corrected figure (Fig. 3) is given as below.

The original article was corrected.

The online version of the original article can be found under doi:10.1007/s00586-017-5211-7.

Yvonne Yan On Lau yonnlau@yahoo.com.hk; lyo590@ha.org.hk; yvonnelau@cuhk.edu.hk Department of Orthopaedics and Traumatology, Prince of Wales Hospital, The Chinese University of Hong Kong, Shatin, Hong Kong

2 Department of Imaging and Interventional Radiology, Prince of Wales Hospital, The Chinese University of Hong Kong, Shatin, Hong Kong

3 Department of Orthopaedics and Traumatology, Tseung Kwan O Hospital, Hang Hau, Hong Kong 


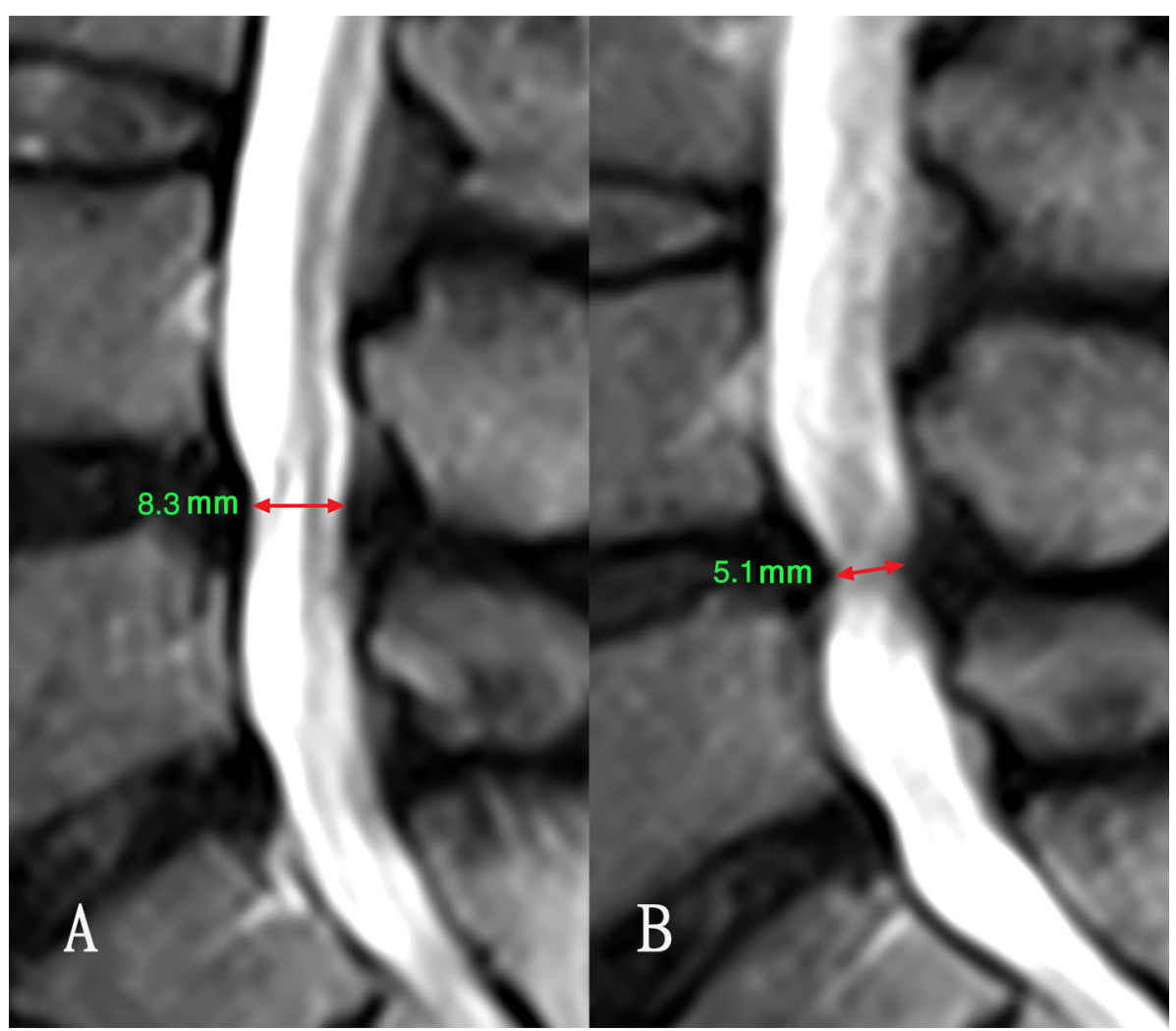

